Ghossaini, B.M., Dehaini, K.Y., Alruzz, M.A., Fakhr Eddine, N.A., and Hamzeh, F., (2017). "An Application for Improved Lean Construction Practices" In: Proc. $26^{\text {th }}$ Annual Conference of the International. Group for Lean Construction (IGLC), González, V.A. (ed.), Chennai, India, pp. 1195-1205. DOI: doi.org/10.24928/2018/0242. Available at: www.iglc.net.

\title{
SYNCLEAN: AN APPLICATION FOR IMPROVED LEAN CONSTRUCTION PRACTICE
}

\author{
Bassem M. Ghossaini ${ }^{1}$, Kazem Y. Dehaini ${ }^{2}$, Mustafa A. Alruzz ${ }^{3}$, Najib A. Fakhr \\ Eddine $^{4}$ and Farook R. Hamzeh ${ }^{5}$
}

\begin{abstract}
Visual management (VM) is instrumental in implementing lean construction philosophy and principles. The lack of communication and sharing of information among construction professionals in construction projects hinders workflow. Visual management improves the performance of workers and optimizes workflow. This paper introduces a mobile application, Synclean, inspired by the virtual Obeya room of Toyota Production Systems (TPS) to ease the transfer of information between site personnel. Synclean will boast a user-based task manager, showing the weekly tasks schedule, covering task descriptions and constraints while including a Kanban-like notification system that addresses tasks for each participant. SyncLean provides the needed platform for signalling the end and start of tasks to those responsible directly, all while holding accessible information in the cloud associated with these tasks like drawings and work methods. These and other features will ensure Synclean is relevant to the very last planner on construction sites and will support collaborative value-adding, wasteminimizing work. The application mobile interface was tested by users and the impact of this application was tested by surveying site personnel of various positions for the application's necessity. Results show the need for a visual tool like Synclean to bridge the communication and information sharing gap between site personnel.
\end{abstract}

1 Undergraduate Student, Civil and Environmental Engineering Department, American University of Beirut, Lebanon,bmg05@mail.aub.edu

2 Undergraduate Student, Civil and Environmental Engineering Department, American University of Beirut, Lebanon, kyd01@mail.aub.edu

3 Graduate Student, Civil and Environmental Engineering Department, American University of Beirut, Lebanon, mar26@mail.aub.edu

4 Undergraduate Student, Civil and Environmental Engineering Department, American University of Beirut, Lebanon,naf14@mail.aub.edu

5 Assistant Professor, Civil and Environmental Engineering Department, American University of Beirut, Beirut Riad El-Solh 1107 2020, Lebanon, Phone +961 1350000 Ext: 3616, Farook.Hamzeh@mail.aub.edu 
Bassem M. Ghossaini, Kazem Y. Dehaini, Mustafa A. Alruzz,

Najib A. Fakhr Eddine and Farook R. Hamzeh

\section{KEYWORDS}

SyncLean, lean construction, application, Information Technology (IT), visual management (VM).

\section{INTRODUCTION}

Today's construction industry features a wide range of clients who demand an even wider spectrum of projects. To meet these demands, full utilization of all available resources is needed. Of these resources is the evolving field of Information Technology (IT) (Sommerville et al., 2007). However, IT alone falls short in deciding the most suitable configurations for the construction industry issues (Sommerville et al., 2007). To better meet the mentioned demands, the construction industry is adopting lean practice which will, if utilized according to recommended guidelines, show considerable improvement to projects (Hamzeh et al., 2012). Bell and Orzen, in the book "Lean IT", mention that a staggering magnitude is spent on poor implementation of IT in projects. The authors explain, that focus on tools without the clear grasp of Lean principles, is like "sailing a ship without a rudder" (Bell et al., 2010). That leads to the realization of the need for lean thinking in information systems (Bell et al., 2010), and the need for a collaboration between the mentioned in today's construction industry.

Through visual management, experts in IT can develop the right user-friendly interphase that will embrace both construction and lean practice in construction. By visualization, core values, goals and culture will be aligned within a project by the stimulation of human senses (Brady et al., 2012). The availability and reliability of mobile phones provide an already existing platform for implementing the mobile application, "SyncLean", proposed in this paper, that will utilize Information Technology and Lean philosophy in the favor of the construction industry. SyncLean will employ visual management tools to help improve construction site workflow, quality and safety by incorporating the latter into a mobile application.

SyncLean, through its features, will ensure flow on construction sites through a proactive view on the construction schedule. The application being a mobile phone accessible application is an overall improvement to the availability of site personnel on site. The application will indirectly reduce waste, knowing site personnel can now "Go and See", Genchi Genbutsu, and spend more time on site, all while using the application. Other principles of the Toyota production system

\section{DEVELOPED/PROPOSED APPLICATIONS ENABLING LEAN THROUGH IT}

Keeping up with the pace of technology, many software applications have been proposed/developed in the field, each aiming at improving the workplace from a different perspective. These applications will ensure better construction practice, from the standpoint of lean theory and practice. Of these software applications are the following, along with some of their features: 
- Simplean (Faloughi, et al., 2014): Featuring process visualization, tasks and their constraints and a drawings viewer, this proposed application promotes transparency between project participants. Other features are live sharing and updating of information about tasks and their prerequisites.

- SwiftKanban ("SwiftKanban - The Best \& Most Powerful Visual Kanban Software", 2018): It is a software that enables visual management, optimizes the work flow and delivers products faster. Communication and collaboration with different parties, analytics and performance tracking are some of the many features offered by SwiftKanban.

- LeanKit ("Kanban Software for Lean Project Management", 2018): This software creates a visual model of the workflow and provides shared understanding of the work status. It features virtual whiteboards to visualize the workflow through cards. Also, it contains collaboration features for asking questions and updating the work status.

- KanBIM (Sacks et. al, 2010): The KanBIM system is a software that aims to control the work flow on construction sites using building information modelling (BIM). It provides a clear visualization and a work status of the planned tasks.

- Instantask (Daou et al., 2015): Instantask is an application that helps in showing emergent tasks that are noticed during execution. It makes these unplanned tasks visible to all users.

- LOSite (Bascoul et al., 2017): LOSite is a location-based scheduling program that aims at visualizing the space between all subcontractors on projects. This program manages the space on site, hence facilitating production control.

What these applications/programs offer is only one of many features that describe a lean execution. Safety in particular, is not tackled by any of the applications or programs mentioned despite being a crucial goal in the Toyota Production System. What is needed in the field of construction, is a comprehensive mobile application combining all the capabilities above and more, into a user-friendly individual-based visual interface, available to even the Last Planner in a project. Such an interface will provide the means of communicating the different aspects of the projects to all its entities, hence further engaging these entities in value addition. SyncLean will provide effortless access to all its features from anywhere on site, without the need to visit site offices or use computers, a luxury that many of the mentioned applications does not make possible.

\section{METHODOLOGY}

The aim of this paper is to propose a new technical tool in the field of Visual Management (VM) and explain why this tool is strongly needed in construction projects. $\mathrm{VM}$ offers solutions to the problems that arise from the lack of communication and slow flow of information, and SyncLean is a visual interphase that will ensure the mentioned obstacles are overcome. The research process will consist of assessing the need for such an application through the review of literature, developing the application interphase and testing of the application features and effectiveness on a small student community and 
some accessible site personnel. The Appery.io online mobile application development platform will serve as a tool to build and develop SyncLean into a functional application that will then be tested for its contribution to construction, lean construction in particular. The performance of SyncLean will finally be rated by a satisfactory survey issued to the previously mentioned users.

\section{SYNCLEAN: AN OVERVIEW}

SyncLean, as revealed, is a visual application that can be used by all construction site personnel. It aims at providing an easy to use visual interphase that will ease the process of construction and optimize the flow of information between the participants. This application will provide (1) the description, constraints, progress of tasks, hazards associated to these tasks and the option to add emergent tasks, (2) a weekly or biweekly look-ahead schedule that can be updated from upstream and downstream, (3) access to useful documents like site plans, drawings and methods of statement, (5) a communication system consisting of messages and tap-to-talk, (6) an Andon system for any problems that pop up and (7) other useful analytical features.

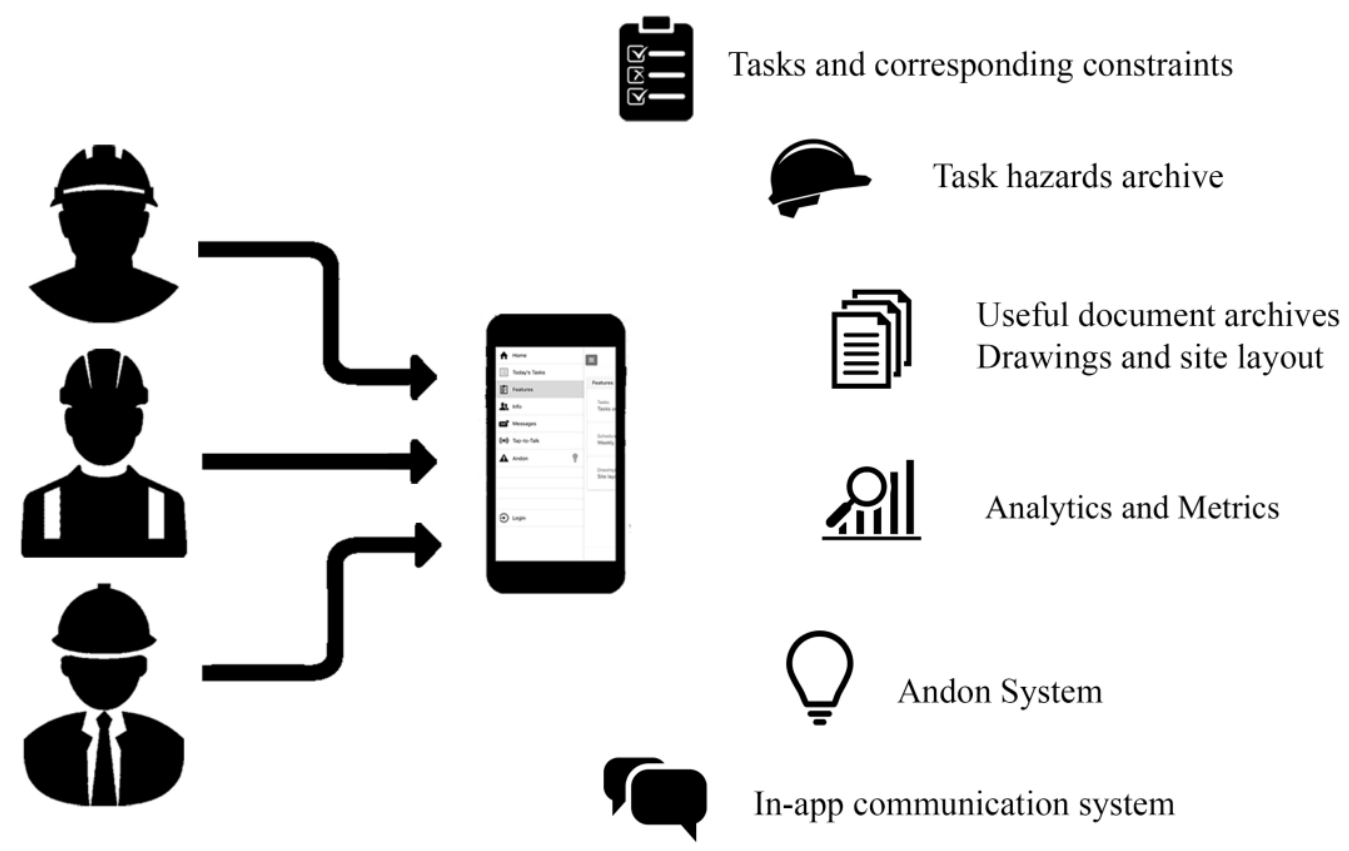

Figure 1: A conceptual model showing the different features offered by SyncLean.

\section{TASKS AND CONSTRAINTS}

SyncLean users will each have a separate account depending on their position in the construction site hierarchy. This will provide every user with only the information relevant to him/her. Tasks then, will be introduced based on the user's role. Each user 
will have access to his own tasks and the tasks that he is related to (predecessor and successors) i.e. tasks related to concrete will be shown to the concrete foreman and steel fixing will show as a predecessor. The application also has a daily tasks page that shows, from the schedule, the tasks to be executed on a workday. As for the tasks themselves, they will each have brief descriptions and their corresponding constraints listed. The mentioned page will also contain a task hazards tab that will link the user to the risks a task he's responsible of might pose. Also, the duration in days or the start and end dates will be included, where the amount of resources needed, type of equipment to be used and where they are located on site is provided. As mentioned before, constraints will appear in the form of tasks for the responsible users. An example would be formwork being a constraint to steel fixing, when the formwork is done by the formwork crew, they will check the task completion box in SyncLean, which will in turn be reflected as a met constraint for the steel fixing foreman. This will be relayed automatically to the steel fixing foreman as a notification. When all task constraints are met, the relevant user will be notified via SyncLean to start a task. This will be done automatically by the application itself. Also, not only will SyncLean list information about the tasks themselves, but also link the task page to the location of the task on the site layout feature that will be discussed in its corresponding section.

\section{SCHEDULE}

Schedules are used to keep track of the work on site. This feature will be accessible by the foreman and engineers. When the daily tasks done are uploaded, the schedule will be automatically updated, showing any delay if present. This guides the calculation of percent plan completed and triggers the personnel in charge to find solutions to increase the pace of work and get back on schedule. SyncLean then, provides upstream and downstream updates of schedule, enhancing the overall rescheduling experience.

\section{DOCUMENTS}

\section{Site Layout and Drawings}

This tab is mainly designed for viewing different sections and plans of the site but is not limited to this. It is divided into two parts, being the Site general layout and specific drawings. Safety being highly considered, the general site layout will contain locations of first aid kits, automated external defibrillators and fire extinguishers. Open shafts will be located on these drawing as a redundant safety measure to ensure an incident-free project. The general layout will also show updated stock locations. Workers don't have to search for materials in case there is no specific lay down area. For an efficient use of space, and to avoid falling into space constraints, the position of different teams working on site will be identified through an in-app location system. The tasks tab will have a site location feature that will show the user where the selected task is on the site layout plan. The other subsection of this feature is the drawings section that will hold plans, sections and longitudinal sections aiding engineers and foremen in their tasks as well as a 3D model that will better explain the site to users. As-built drawings can also be updated regularly to give a visual representation of the completed parts of the project. This will ensure time 
Bassem M. Ghossaini, Kazem Y. Dehaini, Mustafa A. Alruzz,

Najib A. Fakhr Eddine and Farook R. Hamzeh

is not lost attaining drawings from the site offices and will ensure the correct execution of work relating to the now always available drawings.

\section{Methods of Statement}

Quality being taken very seriously, methods of statements are now an indispensable part of construction projects. These documents will guide workers to a defect-free result. Within Synclean, these documents will be easily accessible, where every user is able to access methods of statement that are relevant to him and his discipline.

\section{COMMUNICATION}

For the ideas and practices of lean construction to be successfully disseminated, effective communication is at a premium (Seymour et al., 1997). As such, all the parties within the same project must be connected to each other through several ways that facilitate their modes of communication. The latter is achieved within SyncLean through two features: messages and tap-to-talk. The messages tab is a common platform for all users who are logged in, to chat whenever needed and to receive notices from their superiors. Through this messaging tab, users can easily reach each other for necessary aid or inquiries. In addition to the messages, there is the tap-to-talk button that facilitates instantaneous communication between personnel, it mimics the walkie-talkie system we all know.

\section{ANDON}

Andon is visual management control tool that is used to manage the operation status of the work in the work place (Lean Enterprise Institute, 2008). This definition applies to production systems. Similarly, in construction, this system is used to alert engineers if there is a problem that cannot be solved by workers or foreman. This Andon system consists of three colored buttons. By default, it is set to green, indicating a normal flow of work. When a problem arises, the Last Planner tries to solve it, if it is too complicated, he/she presses the yellow button which directly sends a notification accompanied with an alarm tone to his/her superior. After assessing the situation, if the superior cannot solve this problem, the red button is pressed, and a notification is sent to people higher in the site hierarchy. This feature will provide autonomy and encourage the workers to ask their superiors for help when needed.

\section{ANALYTICS}

Another feature provided by SyncLean is generating a daily report that is available to even the last planner of the project. All that is being monitored on site will be sent to the engineer's inbox as a report. This will be developed into what we know as site daily report. Management can then monitor the performance of the site body by the reports generated by SyncLean.

\section{SURVEY AND DISCUSSION}

\section{SATISFACTORY SURVEY RESULTS}

The application was tested by a small student community at the American University of Beirut and the results turned to be mostly positive. Users praised several aspects, mainly 
the task hazards tab, the Andon/notification system, and the analytical features that automatically generate metrics. The users also reported the ease of use of SyncLean, and the simple design that ensures a fast learning/adaptation process. The below infographics show results from the survey.

Figure 2 shows the users satisfaction with SyncLean where most responses ranged between $4 / 5$ and 5/5 indicating a favourable overall response.

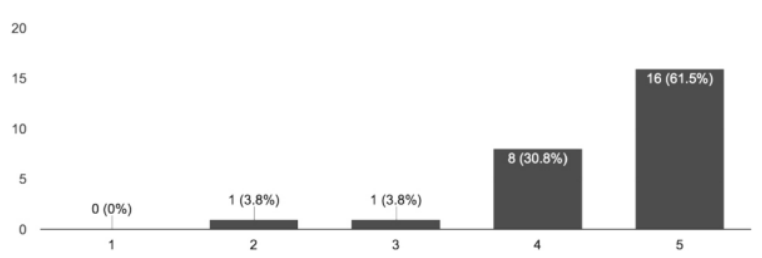

Figure 2: User satisfaction.

Figure 3 shows the most preferred features voted by the users, results indicate that the most favoured feature is the "task hazards archive" followed by the "tasks and constraints" feature.

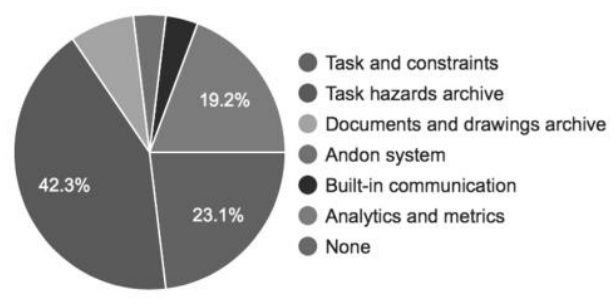

Figure 3: Most preferred SyncLean features.

Figure 4 shows the least preferred features voted by the users, results indicate the "Built-in communication" feature was not highly valued by users.

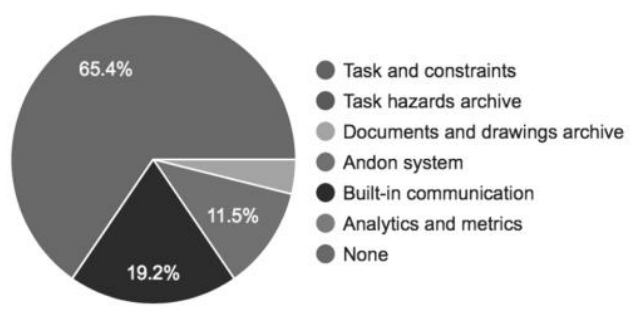

Figure 4: Least preferred SyncLean features. 
Bassem M. Ghossaini, Kazem Y. Dehaini, Mustafa A. Alruzz,

Najib A. Fakhr Eddine and Farook R. Hamzeh

\section{DISCUSSION}

Employing Visual Management, one of the foundations of the Toyota Production System "House Model", SyncLean will help reduce waste, by allowing site personnel to spend more time on site while having access to needed information. The site professionals will be able to "Go and See", Genchi Genbutsu, while having access to the application. Another foundation of the "House Model", that is the standardization of processes, will be tackled through the SyncLean documents archive that will include standard work methods for construction. Through its proactive view on the construction schedule, SyncLean will improve construction flow, with the goal of rendering the flow a continuous just-in-time flow, a pillar in Toyota production. The SyncLean digitized Andon feature, will ensure in-station quality and reduce rework through a fast response to problems, portrayed in the "House Model" as the pillar Jidoka. Some goals of the Toyota Production System, will be made easier to achieve through SyncLean. The Andon feature will push for better quality while the tasks hazards archive feature will ensure a safer work environment. The features of SyncLean will then form a "House Model" of their own, a structurally less complex model, that will hopefully develop to a future model on par with that of the Toyota Production system. This model, will allow for team work through its collaborative nature and ultimately, continuously improve (Kaizen).

The survey showed the interest of users in the safety features provided by SyncLean and the 'task and constraints' feature as well. The latter being direct effectors of project safety and performance, it is only natural these features are favored. The survey results also reflected the ease of use of SyncLean by the users, but the targeted survey body was made of students and teachers. The application ease-of-use is yet to be evaluated by different specialists of different backgrounds and positions in the construction industry hierarchy. The results showed that the least preferred feature was the built-in communications feature, which most of the surveyed found unnecessary in comparison to the already available communication features on the mobile platform. More detailed testing will be conducted when a full version of the application is developed.

As for the application itself, Alarcon et al. (2013) state that managing information is critical for organizational performance, and that information networks are vital for value generation (Alarcon et al., 2013). SyncLean, being the center of construction site information sharing will make way for value generation through accessibility to the Last Planner. Not only will the mobile application provide easy accessibility, but also shorter communication time between the site personnel and decision-making entities through its communication features and virtual Andon system. Hamzeh et. al (2012) state that an agile response to unexpected problems is ensured through shortening the previously mentioned communication time. By achieving a more reliable workflow on site, through SyncLean, schedule performance will be significantly affected. Two case studies confirmed the correlation between workflow reliability and schedule performance through quantitative analysis (Olano et al., 2009). Monitoring the schedule through a user-friendly mobile application, will also simplify the data collection process on site, hence facilitating database creation (Costa et al., 2004). The easily accessible constraints will improve the site personnel understanding of tasks, which will in turn effect the effect 
of look-ahead planning. Even without prior knowledge of Lean philosophy in construction, site personnel will be engaged in making tasks ready and increasing (TMR), which will affect PPC (Percent Planned Completed) positively and reduce the duration of the project (Hamzeh et. al, 2015).

Featuring a task hazard archive, SyncLean will provide workers with detailed hazard descriptions for every task to be executed. Through virtual cloud-based communication, the application will substantially increase levels of safety, knowing the mere daily verbal communication of risks between site personnel ought to affect safety levels significantly (Kines et. al, 2010).

The application being in its preliminary stages, server downtime, application crashing, and any problems related to the IT perspective of this project are being disregarded in this paper.

\section{CONCLUSION}

SyncLean, is a mobile application that aims at improving site work, tackling performance, quality and safety. The application promises features that will ensure tasks are done safely, correctly and on time. The user-friendly nature of SyncLean will ease its release into construction sites and will prove its reliability and importance. The proposed application will hopefully result in a fruitful collaboration between Construction, Lean and Information Technology (IT).

The satisfactory survey taken by the prototype application testers reflected how easy to use SyncLean is. The survey targeted the university students that tested the application and the testers were immediately familiar with the interphase and familiarized themselves with the application features immediately. The task hazards feature was particularly praised by the users alongside the automated analytics and metrics feature.

To conclude, the theoretical analysis for the need of SyncLean is but a step in the course of fully implementing this application in a construction project. Much work is yet to be done however, in terms of fully developing this application and testing it on real ongoing projects. Next steps would be to release a final build of the application that would then be implemented into a construction site for study. Full implementation would serve as a case study that would uncover the weaknesses of SyncLean and show through quantitative analysis whether it would benefit a project. The latter would allow testing of the application interphase on a larger community consisting of different disciplines and education levels. Other future steps would be to consider the technical specifications needed to successfully run SyncLean on mobile devices, and studying the costs associated with developing, implementing, running and sustaining the application from the start to the end of a construction project.

\section{REFERENCES}

Alarcón, D.M., Alarcón, I.M. \& Alarcón, L.F. 2013, 'Social Network Analysis a Diagnostic Tool for Information Flow in the AEC Industry' In:, Formoso, C.T. \& 
Bassem M. Ghossaini, Kazem Y. Dehaini, Mustafa A. Alruzz,

Najib A. Fakhr Eddine and Farook R. Hamzeh

Tzortzopoulos, P., 21th Annual Conference of the International Group for Lean Construction. Fortaleza, Brazil, 31-2 Aug 2013. pp 947-956

Bascoul, A.M. \& Tommelein, I.D. 2017, 'Visualizing Daily On-site Space Use' In:, 25th Annual Conference of the International Group for Lean Construction. Heraklion, Greece, 9-12 Jul 2017. pp 597-604

Bell, S. C., Orzen, M. (2010). Lean IT. New York: Productivity Press

Brady, D.A., Tzortopoulos, P. \& Rooke, J. 2012, 'Using Design Science To Further Develop Visual Management Application in Construction' In:, Tommelein, I.D. \& Pasquire, C.L., 20th Annual Conference of the International Group for Lean Construction. San Diego, USA, 18-20 Jul 2012.

Costa, D.B., Formoso, C.T., Kagioglou, M. \& Alarcon, L.F. 2004, 'Performance Measurement Systems for Benchmarking in the Construction Industry' In:, Bertelsen, S. \& Formoso, C.T., 12th Annual Conference of the International Group for Lean Construction. Helsingør, Denmark, 3-5 Aug 2004.

Daou, E., Gharzouzi, P., Sreih, E. \& Hamzeh, F. 2015, 'Instantask: Designing a Visual Application for Enabling Agile Planning Response' In:, Seppänen, O., González, V.A. \& Arroyo, P., 23rd Annual Conference of the International Group for Lean Construction. Perth, Australia, 29-31 Jul 2015. pp 23-32

Faloughi, M., Bechara, W., Chamoun, J. \& Hamzeh, F. 2014, 'Simplean: An Effective Tool for Optimizing Construction Workflow' In:, Kalsaas, B.T., Koskela, L. \& Saurin, T.A., 22nd Annual Conference of the International Group for Lean Construction. Oslo, Norway, 25-27 Jun 2014. pp 281-292

Hamzeh, F., Zankoul, E., and Rouhana, C., (2015) How can 'tasks made ready' during lookahead planning impact reliable workflow and project duration?, Construction Management and Economics, 33:4, 243-258, DOI: 10.1080/01446193.2015.1047878

Hamzeh, F., Ballard, G. and Tommelein, I. (2012). Rethinking Lookahead Planning to Optimize Construction Workflow, Lean Construction Journal, pp. 15 - 34.

Kanban Software for Lean Project Management. (n.d.). Retrieved February, 2018, from https://leankit.com/

Kines, P., Andersen, L., Spangenberg, S., Mikkelsen, K., Dyreborg, J., Zohar, D., Improving construction site safety through leader-based verbal safety communication, Journal of Safety Research, Volume 41, Issue 5, 2010, Pages 399-406, ISSN 00224375, https://doi.org/10.1016/j.jsr.2010.06.005.

Lean Enterprise Institute (2008). Lean Lexicon: a graphical glossary for Lean Thinkers. The Lean Enterprise Institute, Cambrigde, 126pp

Lee, S., Diekmann, J.E., Songer, A.D. \& Brown, H. 1999, 'Identifying Waste: Applications of Construction Process Analysis' In:, 7th Annual Conference of the International Group for Lean Construction. Berkeley, USA, 26-28 Jul 1999. pp 63-72

Olano, R.M., Alarcon, L.F. \& Razuri, C. 2009, 'Understanding the Relationship Between Planning Reliability and Schedule Performance: A Case Study' In:, Cuperus, Y. \& Hirota, E.H., 17th Annual Conference of the International Group for Lean Construction. Taipei, Taiwan, 15-17 Jul 2009. pp 139-153 
Seymour, D., Rooke, J. \& Crook, D. 1997, 'Doing Lean Construction and Talking About Lean Construction ' In: \& Tucker, S.N., 5th Annual Conference of the International Group for Lean Construction. Gold Coast, Australia, 16-17 Jul 1997. pp 53-62

Sommerville, J., Craig, N. (2007). Implementing IT in Construction. London: Routledge. SwiftKanban - The Best \& Most Powerful Visual Kanban Software. Retrieved February, 2018, from https://www.digite.com/swiftkanban/

Tezel, A., Koskela, L.J. \& Tzortzopoulos, P. 2013, 'Visual Management in Industrial Construction a Case Study' In:, Formoso, C.T. \& Tzortzopoulos, P., 21th Annual Conference of the International Group for Lean Construction. Fortaleza, Brazil, 31-2 Aug 2013. pp 471-480 